\title{
"QUEM PODE MAIS DO QUE DEUS?": AS CRIANÇAS CAPUXU E SUAS EXPERIÊNCIAS COM OS MALASSOMBROS
}

\author{
Emilene Leite de Sousa ${ }^{1}$ \\ ${ }^{1}$ Programa de Pós-Graduação em Sociologia, \\ Universidade Federal do Maranhão, Brasil
}

\section{Apresentação}

Este artigo se compõe de parte da minha pesquisa de doutorado cujo objetivo era analisar a produção da pessoa capuxu à luz da fabricação dos corpos das crianças. Com o intuito de compreender os aspectos gerais desta produção da pessoa, com um olhar voltado para os investimentos feitos nos corpos desde a infância, resvalei nas representações sobre corpo e alma, estas duas dimensões da pessoa capuxu.

A partir disso passei a me dedicar às compreensões das crianças sobre a alma, sobre o que ocorre com ela após a morte e sobre como a definição de pessoa passa inevitavelmente pela não dissociação entre corpo e alma. Assim, discutir a noção de pessoa através das crenças das crianças caperpassa as categorias corpo e alma e, na categoria alma, se revela o conceito de malassombro. ${ }^{1}$ Por isso, abordo a categoria nativa malassombro através de um diálogo com as noções de pessoa, alma, corpo, morte e medo.

Por meio de um roteiro que me foi ofertado pelas crianças, segui na produção de uma etnografia sobre os malassombros, as casas malassombradas, os sonhos de aviso apresentando uma das facetas da produção da pessoa capuxu segundo o olhar das crianças e de suas agências. Com isso, , pretendo demonstrar que os Capuxu - como os Daribi - ao tratarem da noção de pessoa "representam os mortos sob a forma de fantasma porque as pessoas e as relações é que são importantes" (Wagner 2010:60). 
Assim, ao mesmo tempo em que os Capuxu prezam a relação com os animais ou o ambiente (Sousa 2017), prezam por ela também com as pessoas durante a vida e mesmo após a morte nesta sociedade relacional. Por esta razão, as crianças atribuem às almas comportamentos, visões, compreensões e decisões de pessoas.

Afirmo não haver uma relação direta entre os malassombros que assustam as crianças capuxu e a religiosidade, estando as concepções e as operacionalizações do termo separadas de qualquer processo de cristianização, ao contrário dos achados de Pires entre crianças e adultos de Catingueira (Pires 2009, 2011). O que estaria por trás dos malassombros entre as crianças capuxu seria a valorização das pessoas e suas relações e o não esquecimento dos familiares mortos que, de alguma maneira compartilhando espaços e horários junto aos vivos, aparecendo em visitas rápidas e aparentemente indesejadas - se mantêm por perto reacendendo a sua memória.

Analiso também a agência ${ }^{2}$ das crianças no que se refere à criação do malassombro e aos modos de lidar com ele, revelando a autonomia que elas apresentam (Sousa 2019). Apesar das histórias, dos significados ou do próprio temor do malassombro ser ensinado pelos mais velhos, representando um conhecimento intergeracional - sem negar sua transmissão através das próprias crianças - o fato é que estas exercem uma agência, com autonomia relativa, ao criarem estratégias próprias para lidar com os malassombros que não são de conhecimento dos adultos, ao mesmo tempo em que elas também são responsáveis por criar determinados malassombros tidos como especialmente infantis.

Apesar de existirem diversos tipos de malassombros, eu me dedico a pensar especialmente na alma dos mortos, definida em termos nativos como alma-malassombrada, como malassombro principal dentre os que figuram entre os Capuxu, dada a centralidade com que ela aparece nas conversas das crianças e também pela sua relação com a noção de pessoa e a capacidade de assombrar crianças e adultos.

Para os Capuxu, malassombro diz respeito a um conjunto de acontecimentos, visões, barulhos e tudo o que, sendo sobrenatural, assusta-os. Dentro desse rol de malassombros encontramos a alma-malassombrada que é o equivalente a fantasma ou alma penada em outras localidades. Entre os Capuxu a expressão "alma" diz respeito tanto a alma dos vivos como a dos mortos, sendo as últimas malassombradas. A utilização do mesmo termo para designar almas vivas ou mortas revela como elas ocupam os mesmos espaços e habitam a mesma sociedade. São, de certa forma, indistintas, sendo atribuídas às almas dos mortos inclusive características da pessoa. 
Preciso, pois, diferenciar a alma dos vivos - embora quando em vida mal se lembrem que possuem alma - daquela dos mortos que viram alma. Para fins didáticos, me apropriarei da expressão nativa alma-malassombrada (respeitando a pronúncia capuxu) sempre que me referir à alma dos mortos.

Neste artigo estabeleço um diálogo especialmente com Pires (2009, 2010, 2011), cuja pesquisa de campo sobre mal-assombros ocorre em Catingueira, situada a 16 quilômetros do Sítio Santana-Queimadas dos Capuxu. O contraponto tecido com a pesquisa de Pires é fundamental e, através dele, cheguei a importantes conclusões na pesquisa.

O título deste trabalho, uma frase proferida pelas crianças, embora mencione Deus, não sugere uma conexão direta entre religiosidade e malassombro para as crianças capuxu - conforme tentarei demonstrar ao longo do artigo - sendo apenas uma expressão comumente repetida nos casos de aparição de almas-malassombradas, ensinadas às crianças pelos adultos para afugentar esses seres sobrenaturais que povoam o Sítio Santana-Queimadas.

Inserido no campo da Antropologia da Criança, este artigo vislumbra ser uma contribuição na defesa do ouvir as crianças como uma variável em campo, de modo que qualquer objeto a ser investigado, se não considerar as crianças, não terá alcançado uma visão completa da realidade ( Schildkrout 1978).

Compreendo que não existem universos adulto e infantil separados, ou a existência de uma cultura infantil, como defendia Fernandes (2004), mas crianças e adultos habitam o mesmo universo. Todavia, embora em algumas situações compartilhem dos mesmos sistemas de crenças, concedem sentidos diferentes a estes sistemas que devem ser considerados, ou seja, por um lado, não se pode isolar as crianças dos adultos em campo, por outro lado, não se deve acreditar que o compartilhamento de códigos comuns tenha o mesmo sentido para as duas categorias. Devemos considerar as particularidades das representações, percepções e experiências de adultos e crianças de maneira dissociada, quando necessário.

\section{Capuxu: de vespa social a grupo social}

Desde o início dos anos 2000 tenho me dedicado a estudar o povo Capuxu, tendo sido a única antropóloga entre eles. De análises sobre a juventude rural na iniciação científica até as pesquisas de mestrado e doutorado (Sousa 2004, 2017), tenho me interessado pelas mais diversas questões sobre eles, como aquelas sobre a experiência das crianças com a 
infância - o trabalho e a ludicidade - e a fabricação do corpo e a produção da pessoa capuxu em seus vários aspectos - gestão onomástica, apadrinhamento, parentesco, contiguidade territorial, etnônimo etc. - culminando na produção de uma etnicidade capuxu.

O povo Capuxu, que reside no sertão da Paraíba, constitui um grupo cuja diferenciação está nitidamente marcada pela produção de fronteiras e por um sentimento de pertença ao povo. Neste sentido, utilizo-me do instrumental teórico de Barth (2011), que se dedicou à análise dos grupos étnicos através de suas fronteiras, deslocando a ênfase do centro dos grupos - através de seus sinais diacríticos - para as fronteiras onde os grupos se definiram através do contato e da negação de outros grupos. Tomando as teorias da etnicidade como um horizonte, tenho me interessado pela construção da identidade capuxu, circunscrita pelas fronteiras que estabelecem a diferenciação entre os Capuxu e os outros, ${ }^{3}$ o sentimento de pertença que envolve o grupo e os chamados sinais diacríticos: a aparência comum; o sotaque diferenciado; a endogamia com união preferencial entre primos; o etnônimo e a contiguidade territorial (Sousa 2020).

Segundo o povo Capuxu, o primeiro habitante do local teria sido um baiano, o que justificaria o sotaque do povo caracterizado pela lentidão com que pronuncia as palavras. ${ }^{4}$ A comunidade consta de quase 200 habitantes, com praticamente quatro sobrenomes: Ferreira, Menezes, Lima e Costa, isto em decorrência do sistema endogâmico de parentesco com casamento preferencial entre primos legítimos e carnais. ${ }^{5} \mathrm{O}$ sistema endogâmico de parentesco constitui-se em mais um dos elementos de afirmação étnica do povo Capuxu que os diferencia dos outros, cujo casamento com primos é visto como pecado e produtor de filhos com necessidades especiais.

No que diz respeito ao etnônimo Capuxu, este lhes foi dado por conta de um de seus antecessores, que se chamava João e tinha como hábito a caça de abelha da espécie Capuxu, de modo que o apelido João Capuxu lhe foi concedido pelo povo das redondezas e repassado de geração a geração.

\section{Do corpo e da alma: sobre a produção da pessoa capuxu}

As variações na definição de pessoa - esta "categoria do espírito humano", nos termos de Mauss (2003 [1969]) - são enormes, de sociedade para sociedade, portanto, esta visão ocidental é algo extremamente particular e histórico. Para Mauss, a pessoa humana, construída a partir da noção de uno, como o próprio Deus, seria constituída de substância e modo, corpo e alma, consciência e ato. 
A perspectiva cartesiana, ao separar radicalmente as dimensões corpo e alma, reforça o funcionamento independente da essência, passando o corpo para os domínios biológicos (Silva 1999). Os Capuxu entendem que o corpo e a alma são dissociados após a morte, deixando de constituir a pessoa. Entendo que o sistema de crenças capuxu, em especial os malassombros, revela as representações acerca da pessoa, sinalizando quais as concepções que vigoram na comunidade a respeito da alma, uma das dimensões da pessoa.

Se os Capuxu entendem que a pessoa é formada de corpo e alma, a crença nesses malassombros denuncia a ideia de que a alma sobrevive após a morte do corpo, que ela não estaria necessariamente vinculada a ele, sendo possível habitar determinados lugares, inclusive espaços como casas, cemitérios, matagais, e aparecer para pessoas vivas, sendo esta alma, a alma-malassombrada.

Em sua pesquisa sobre religião e infância no semiárido paraibano, Pires (2011) apresenta a definição de mal-assombro para os adultos do lugar como "a alma de uma pessoa que faleceu e que, por algum motivo, estabelece contato com os vivos" (Pires 2011:105). Assim, percebemos que a definição dos adultos catingueirense de mal-assombro está restrita à alma. No caso capuxu, esta definição se estende a outros elementos além das almas-malassombradas, como visões, vultos indefinidos, sons, sonhos, comunicações dos seres em geral com os Capuxu etc. Lembro que malassombro é uma categoria nativa manipulada pelos adultos e crianças, não havendo, portanto, um termo equivalente na literatura antropológica, uma vez que esta categoria para os Capuxu não corresponde às almasmalassombradas por não se restringir a elas apenas, havendo uma série de possibilidades de mal-assombrar o outro. O malassombro inclui várias dimensões assustadoras e a alma do morto, que das dimensões do malassombro é a mais referenciada.

Embora encontremos semelhanças entre a definição de mal-assombro dos adultos e das crianças de Catingueira, onde pesquisou Pires, e a dos Capuxu, há algumas diferenças a serem mencionadas. No caso de Catingueira, a produção e a compreensão do mal-assombro pelas crianças se desenvolvem junto ao processo de cristianização, de modo que a noção de mal-assombro se une à ideia de religião (Pires 2009, 2010, 2011). Focada mais na compreensão das crianças capuxu do que na dos adultos, percebo que não há uma relação direta entre a compreensão de céu, inferno, bem, mal, Deus e Demônio para a manipulação do conceito de malassombro operacionalizado por crianças - num rol de possibilidades a ser ainda mencionado - mas tendo como centro focal da categoria a ideia da alma de alguém que já morreu. Já Pires havia observado que até os 7 anos de 
idade as crianças de Catingueira não pareciam "dialogar com o conceito de alma versus corpo" (Pires 2009:301): "A ideia da existência da alma e da sua sobrevida após a morte do corpo é um conceito que leva algum tempo a ser assimilado - assim como os conceitos de bem e mal, Demônio e Deus" (Pires 2009:301). Para Pires, ocorre paralela à cristianização das pessoas a cristianização dos mal-assombros, ao mesmo tempo em que esta cristianização marca uma passagem das crianças aos adultos:

Em se tratando dos malassombros, este seria o limiar entre as crianças e os adultos: as primeiras tornamse adultas no momento em que passam a cristianizar os malassombros. A cristianização dos malassombros coincide com a constatação de que os outros malassombros (citados anteriormente) não são de fato reais e, por isso, não apresentam perigo (Pires 2009:301).

Embora não encontremos uma literatura sobre malassombros nas ciências sociais, há uma variedade de literaturas que se dedicam a pensar a vida após a morte nas concepções infantis numa perspectiva cognitiva. Um exemplo disso é o texto de Bering (2003:246), que problematiza: "[...] o que é um fantasma além de um morto invisível com uma mente?". ${ }^{6}$ Conforme o autor, na teoria de Pascal Boyer, "[...] permanece sem equívocos que fantasmas não deveriam ser diferentes de pessoas vivas quando se trata de funcionamento psicológico básico, pelo menos como são representados nas mentes humanas" (Bering 2002:267). ${ }^{7}$ Boyer define fantasmas: "o conceito [fantasma] é aquele de uma pessoa que tem propriedades físicas contraintuitivas. Diferente de outras pessoas, fantasmas podem passar através de objetos sólidos como paredes. Mas perceba que, afora esta capacidade, fantasmas seguem, de modo bem estrito, o conceito intuitivo comum de PESSOA" (Boyer 2001:73). ${ }^{8}$

Assim, Bering (2003) atenta para a questão de que os fantasmas teriam semelhanças com as pessoas no que se refere ao funcionamento psicológico básico, ou assim os representam as mentes humanas, enfatizando que os fantasmas seguem o conceito intuitivo comum de pessoa. Observo, como Bering, que a definição de malassombro, especialmente na sua subespécie alma-malassombrada, está completamente fundada no caso das crianças capuxu e na noção que compartilham de pessoa. Embora a alma-malassombrada não seja entendida como uma pessoa por não deter um corpo, opera com o raciocínio da pessoa, pois as crianças atribuem a ela comportamentos, visões, compreensões e decisões de pessoas, ou seja, às almas-malassombradas são destinados atributos da pessoa, inclusive o bem e o mal, entendidos pelas crianças como características da natureza humana, independente dos processos de cristianização. 
Logo, as crianças afirmam que elas não são pessoas, mas lhes imputam características de pessoa dissolvendo as fronteiras entre pessoas e não pessoas.

Com efeito, o sistema de crenças em malassombros, em especial a almamalassombrada, denota representações acerca da pessoa. Mas, devemos reforçar, alma não é uma pessoa, e não o é "porque não tem corpo", como me disse uma criança capuxu. De modo que só podem ser designados como pessoas aqueles que possuem corpo e alma juntos, uma alma materializada em um corpo "de carne e osso", capazes de serem vistos e tocados, sendo esta a condição primeira para existir enquanto pessoa, segundo as crianças. É assim que a produção da pessoa passa pelo corpo que é fabricado, mas que contém sempre uma alma presa a ele, sem a qual ele vira corpo de defunto, alma esta cuja condição de existência como pessoa exige que ela esteja aportada em um corpo.

Dalmaso (2018) também se dedicou a analisar a diferença entre pessoas e os Iwa, espíritos presentes em Jacmel no Haiti:

Uma diferença importante entre as pessoas e os lwa reside no fato de os segundos serem invisíveis. Eles não possuem um corpo, mas, ao contrário, têm a capacidade de fluir por diferentes matérias, sejam elas de um animal, de uma pedra ou de um humano. Além disso, eles são onipresentes, podendo estar em diferentes lugares ao mesmo tempo (Dalmaso 2018:108).

Embora nesta pesquisa me interessasse especificamente a fabricação da pessoa por meio das produções dos corpos, não pude deixar de refletir sobre a alma entre os Capuxu e as suas teorias sobre ela que desembocam no malassombro. ${ }^{9}$ Afinal, como já haviam demonstrado Godoi e Mello (2019), a copresença de seres intangíveis e humanos revela-se central em diversos contextos, seja em narrativas e discursos, seja em corpo e na construção de pessoas ${ }^{10}$ onde o domínio espiritual e mundano se intersecionam. Sobre este entrelaçamento os autores afirmam:

Não apenas as pessoas participam umas das outras, mas outros seres também; pois longe de estarem confinados a cosmologias, sistemas de ideias, representações e planos de existência cerrados, entes espirituais estão imersos no mundano e participam ritual e cotidianamente da vida dos humanos. [...] Seres intangíveis estão continuamente em movimento no tempo e no espaço, traçando caminhos e forjando (novas) relações, tanto no plano terreno quanto no espiritual (Godoi \& Mello 2019:3). 
Dalmaso (2018) também se esforça por "recuperar sentimentos, opiniões, saberes e práticas em que os lwa são parte fundamental da experiência social das pessoas, atingindo-as diretamente, influenciando suas ações e interferindo em seus destinos" (Dalmaso 2018:98). "Antes de tudo, a existência dos lwa é um fato de experiência (Pouillon 1979) e, apesar de sua qualidade etérea, não devem ser tomados como entidades abstratas localizadas em um plano deslocado da experiência social humana (Dalmaso 2018: 108).

\section{A morte, o medo e o medo da morte}

Pensar os malassombros entre as crianças capuxu nos obriga a considerar outras categorias analíticas intrínsecas ao termo: a ideia de morte e a ideia de medo. É imprescindível pensar o malassombro capuxu, especialmente o que chamamos aqui de alma-malassombrada, a partir das concepções de morte e medo que se configuram socialmente.

Conforme Bauman, "todas as culturas podem ser codificadas como mecanismos engenhosos calculados para tornar suportável a vida com a consciência da morte" (2008:46). O mais comum e maior deles é negar a morte como fim e acreditar que a vida não acaba com a morte, que é só uma passagem desse mundo para outro. Assim, os mortos continuarão existindo, mas de uma forma diferente.

Uma das maneiras encontradas para controlar a morte é explicar a sua causa. As concepções de boa morte ou má morte e a ideia de que a maneira como se vive definirá o que ocorrerá depois da morte também são modos de controlar a morte. Logo, para alguns cristãos, apenas aqueles que morressem de uma morte anômala poderiam ficar a vagar, podendo se apresentar perante os vivos. Segundo Delumeau,

[...] tinham particular vocação para a vagueação post mortem todos aqueles que não se haviam beneficiado de um falecimento natural e, portanto, tinham efetuado em condições anormais a passagem da vida à morte - logo, defuntos mal integrados a seu novo universo (Delumeau 1996:95).

Entretanto, de acordo com Eloísa Martín, não apenas as almas vítimas de mortes trágicas podem ser acionadas pelos vivos.

Mas, como vimos, não é apenas a morte anômala que permite a ação de quem transpôs a fronteira da vida, pois, para os nativos, para qualquer morto podem ser pedidos favores e, dentro de acordos similares de etiqueta e possibilidade, eles vão atender a esses pedidos (Martín 2001:241). 
Aqueles que sofressem morte natural, não trágica, fariam o caminho direto para o céu, sem vagar pelo mundo. Em todo caso, desde sempre, desejamos acreditar que a morte não seja o fim, esta sendo, talvez, a função social da alma-malassombrada, que atua como uma esperança, uma evidência de que a morte não é o fim. Vê-la pode ser um modo de acreditar que depois da morte nós continuamos existindo de alguma forma em outro lugar. A figura do fantasma representa a existência além da morte (Braite 2019).

Segundo Bauman (2008), o medo é o nome que damos para a nossa incerteza. Ele cumpre a função de instigar a curiosidade humana natural pelo que assusta, sem colocar sua própria integridade em risco. Nunca se soube, entre os Capuxu, que um fantasma tenha feito qualquer mal a alguém. Ora, assim, é possível sentir medo, sem que sua segurança esteja em risco. A alma-malassombrada capuxu é, sem dúvida, um dos mais significativos malassombros por estar envolto em penumbra de mistério e imaterialidade, já que o seu caráter é não corpóreo, o que favorece o medo.

O medo é mais assustador quando difuso, disperso, indistinto, desvinculado, desancorado, flutuante, sem endereço nem motivos claros; quando nos assombra sem que haja uma explicação visível, quando a ameaça que devemos temer pode ser vislumbrada em toda parte, mas em lugar algum se pode vê-la (Bauman 2008:08).

Consoante Braite, o medo da morte faria do fantasma uma figura amedrontadora e desejada, pois os fantasmas apareceriam como a representação da existência além da morte. "O fantasma apareceria assim, diante dos vivos, como uma prova da continuidade da vida" (2019:19) - ao mesmo tempo em que assustam, os fantasmas encarnam o nosso desejo de viver de alguma forma, em algum lugar, após a morte.

O mais importante é que precisamos pensar sobre a relação entre os vivos e a figura do fantasma. Quando vivos e mortos se reencontram, "o laço que se espera que separe os vivos dos mortos é atado, a conexão não é cortada: o medo de que este morto possa vir a cobrar satisfações, [...] vingar-se ou até mesmo impor a sua condição de não vivo no mundo dos vivos causaria repulsa ao outro" (Braite 2019:20), sobretudo porque se pretende negar aquilo que é diferente de mim, mas, no futuro, eu serei como ele.

Citando Freud, Bauman afirma que as sensações de ameaça vêm de três direções: do nosso próprio corpo, fadado à degradação; do mundo externo, que pode nos assolar com forças destrutivas; e o medo do outro, do diferente. O fantasma seria assim uma representação dos três: da morte por ter vindo dela; do perigo do mundo por ser uma força externa; e do desconhecido e 
diferente em relação ao corpo físico dos vivos (Bauman 2008). Só o fato de o fantasma ser uma criatura que passou pelo véu da morte e fez o percurso de volta para contatar os vivos faz com que se concentre nessa figura um conjunto de outros medos, pois "o medo primal da morte talvez seja o protótipo ou o arquétipo de todos os outros medos" (Bauman 2008:73).

Delumeau (1996) trata dos medos que assolaram a Europa e se estenderam ao Novo Mundo, entre eles, o medo de fantasmas. Segundo o autor, uns são bons e trazem mensagens benéficas, enquanto outros trazem pestes, febres, tempestades e trovão, além de fazerem sons no ar para nos assustar.

Os relatos e os transtornos vividos na época fomentam os medos humanos. São esses eventos que propiciam histórias em que tudo o que está acontecendo provém de uma punição, ou beira o fim da vida humana. Independente dos problemas que atormentavam o passado, sempre pairou uma negatividade a respeito da morte e do destino do corpo. Através desses fatos é possível perceber uma preocupação sobrenatural, como se o morto pudesse voltar à vida e até mesmo recobrar algo ainda de sua vida (Delumeau 1996:93).

\section{Segundo Rodrigues,}

o certo é que o morto, como as coisas insólitas, anormais ou ambíguas, constitui um ser impuro, cujo contato representa perigo para o mundo das normas. Em muitas sociedades, ameaça manchar todos e tudo que têm ou tiveram contato com ele - incluindo os seus pertences - já que tudo que se relaciona com ele participa de sua perigosa personalidade: se ele é tabu, são também tabu suas propriedades, sua casa, seus parentes, seus amigos. Estes, segundo os casos e em grau variáveis, se tratam com cuidados especiais, se evitam, se destroem ou se purificam (Rodrigues 2006:52).

Penso que acreditar ver a alma do morto depois de sua passagem trata-se de mais uma dessas estratégias "por intermédio das quais o grupo reafirma por meio do morto a solidariedade do grupo a que ele pertenceu" (Rodrigues 2006:55). Isto se faz necessário porque, conforme Rodrigues, a morte é uma força desagregadora.

Como fenômeno social, a morte consiste na realização do penoso trabalho de desagregar o morto de um domínio e introduzi-lo em outro. A feitura deste trabalho exige toda uma desestruturação e uma reorganização das categorias mentais e dos padrões de relacionamento social (Rodrigues 2006:54). 
Ao analisar as experiências das crianças capuxu com os malassombros, através das quais elas constroem representações sobre a morte, o medo e a alma, desvela-se para mim um universo de crenças que não está restrito às crianças, mas a todo o povo Capuxu, cuja compreensão se tornou mais acessível para mim através das crianças, pois elas, ao contrário dos adultos, não têm constrangimento em falar dos medos dos malassombros e analisar criteriosamente os atributos e as formas do seu agir através de padrões que as ajudam, inclusive, a criar astutamente estratégias para deles escapar. ${ }^{11}$

\section{Almas-malassombradas}

De todos os malassombros que amedrontam os Capuxu, especialmente as crianças, a alma-malassombrada é, de longe, o maior. Para os adultos, poderíamos dizer, o mais eficaz, dada a sua funcionalidade em fazer com que as crianças obedeçam ao ameaçá-las com as aparições de almasmalassombradas: "se você desobedecer, a alma de finada Maria vem te visitar de noite"; "menino que não se comporta as almas-malassombradas vêm puxar os pés de noite". Logo, a alma-malassombrada é também uma aliada dos pais em suas tentativas de educar as crianças.

Em Catingueira, Pires afirma que para os adultos o mal-assombro-alma, se for de um conhecido finado, não deve causar tanto medo.

Para o adulto, como vimos até agora, até mesmo o malassombro enviado por Deus assombra - com a diferença de que esse assombramento não deve perdurar. Quando um malassombro é enviado por Deus, ele deve assustar somente no momento em que se apresentar e tornar explícitas as suas intenções. Depois disso, o malassombro pode até tornarse uma companhia que presta auxílio e proteção. Parcialmente, o medo das almas pode ser entendido pela sua ligação com o desconhecido. Quando existe alteridade, o medo está presente, mas quando identificamos a alma malassombrada e, por consequência, os seus objetivos, o medo tende a se dissipar (Pires 2011:303).

Num contraponto a Pires, afirmo que, entre os Capuxu, adultos e crianças temem as almas-malassombradas e acreditam nelas de igual maneira. Além disso, para adultos ou crianças, o medo está presente seja a alma-malassombrada conhecida ou não. Entretanto, os sentidos atribuídos à existência dos fantasmas e às suas agências variam de adultos para crianças. ${ }^{12}$

No caso dos adultos - com o processo de cristianização cumprido e praticantes do catolicismo, frequentadores da Igreja de Sant'Ana, padroeira local - toda alma-malassombrada é associada às noções cristãs de Deus e 
Demônio, bem e mal, céu, inferno, purgatório e a definição da pessoa que ela foi enquanto viva. Segundo Pires, em Catingueira,

No caso dos católicos, os malassombros podem ser associados ao bem se revelam almas de pessoas que foram conhecidas em vida; neste caso, serão mesmo associadas primordialmente ao bem. Se, ao contrário, não foram pessoas conhecidas, serão tendenciosamente associadas ao mal (Pires 2009:303).

Entre os Capuxu, mesmo sendo batizadas as crianças desde tenra idade, o modo como elas se relacionam com os malassombros é diferente, não estando a experiência permeada por noções de bem, mal, pecado, paraíso. Para elas, toda alma-malassombrada deve ser temida, sendo ela conhecida ou não. "Sua ontologia está toda definida no seu próprio nome: ele assombra" (Pires 2011:304). Afinal, elas tudo fazem para não ver a alma da "finada Tequinha", tão amada por todos. Ainda assim, como me disse um deles entre as gargalhadas infantis, "o medo é maior do que o amor", embora o medo seja, em todo caso, o fio que une os vivos às almas-malassombradas.

Conforme atesta Pires em Catingueira, as crianças pequenas não se perguntam sobre a intenção de um mal-assombro (Pires 2009). Já as crianças capuxu, nas conversas noturnas que estabeleciam comigo deitadas nas calçadas das casas olhando o céu estrelado, me falavam sobre a intenção das almas-malassombradas: "é pedir rezas, assustar". A função dos malassombros para as crianças é assustar, não apenas as almas-malassombradas, mas os malassombros de modo geral, mesmo aqueles inventados pelas crianças, os especificamente infantis, aqueles que existem porque foram inventados!

Para a criança pequena, o desenho não representa um malassombro; é o malassombro. Uma vez, durante o trabalho de campo, uma criança desenhou um monstromalassombro dizendome que já o tinha visto. Perguntei onde ela tinha visto aquele malassombro, ao que ela respondeu que ali não existia monstro. Indaguei: "E como foi que você já viu um?". E ela respondeu: "Eu desenhei!" (Pires 2009:307).

Assim, as crianças brincam de assustar umas às outras e também de assustar a si mesmas. Afinal, "as crianças, ao contrário dos adultos, sabem inventar o mal-assombro e o próprio medo" (Pires 2009:306). Ora, se este medo habita a mente de todos aqueles que vivenciam a vida na zona rural no sertão, adultos, idosos, homens e mulheres, o que dizer das crianças, cuja imaginação e faz-de-conta já são férteis, e uma de suas principais ferramentas de produção e leitura de mundo? 
Onde estão duas ou mais crianças capuxu reunidas, nas noites do Sítio Santana-Queimadas, certamente se contará uma história de malassombro com o intuito de propagar o medo, compartilhá-lo e atemorizar aqueles que a ele ainda resistem. Assim é que todo terror é vivenciado com um pouco de humor pelo povo Capuxu. Ocorre que, além de terror, há certa jocosidade nos Capuxu ao tratarem do malassombro em afirmações feitas pelas crianças, umas para as outras, como: "parece um malassombro"; "quanto você cobra pra assustar uma casa?"; "parece uma alma".

A experiência que se estabelece entre o povo Capuxu e os malassombros está diretamente vinculada à preocupação com a alma da pessoa, especialmente quando ela parte. Por isso, o malassombro que mais temem as crianças capuxu são as almas-malassombradas, que dizem respeito às almas de pessoas mortas que, por alguma razão, não foram para o céu. Como se sabe, somente as almas de crianças pequenas vão direto para o céu, porque elas são inocentes, sem pecado, e viram anjinhos - desde que sejam batizadas, do contrário, se morrerem pagãs, as crianças não irão para o céu. Mesmo assim, não há quaisquer registros de almas de crianças que tenham aparecido, elas nunca foram vistas e nem voltam para "pedir reza".

No que diz respeito aos adultos e especialmente aos velhinhos visto que as almas destes são as mais vistas - se passeiam pela Terra e se materializam para pessoas é porque muito provavelmente, como creem os Capuxu, esta alma "se perdeu no caminho para o céu", ou por outras razões não pôde entrar lá: tinha coisas malresolvidas aqui na terra, precisava dar um recado a alguém, ou pecou muito e por isso precisa pedir reza. Isto serve tanto para aqueles que morrem de maneira trágica como para os que cumpriram sua função na Terra e "morreram de velhice". Ainda assim, ninguém está tão velho ao morrer a ponto de não deixar nenhuma pendência na vida, dizem os Capuxu.

Assim sendo, das almas que aparecem, a maioria é aquela que precisa, segundo os adultos, "pedir rezas". ${ }^{13}$ Se conseguirem a quantidade de rezas suficientes para serem perdoadas de seus pecados, pode ser que consigam entrar no céu, objetivo maior dos adultos capuxu. Exatamente por isso é que as almas parecem optar por "pedir reza" principalmente às crianças, pois elas têm crédito com Deus por serem consideradas mais puras e ingênuas do que os adultos: são inocentes. ${ }^{14}$

Assim é que as noites no Sítio Santana-Queimadas são repletas de gritos estridentes de crianças ou silêncios ensurdecedores, quando as crianças se escondem embaixo de lençóis em suas redes enquanto transpiram de tanto calor, mas sem nunca retirá-los para dar uma espiadinha do lado de fora. Embaixo dos lençóis elas se sentem seguras, conforme disseram. 
Estas almas aparecem sempre de roupa branca, geralmente vestido se for mulher, e calça e camisa branca se for homem. E têm sempre a aparência exata de quando morreram: cabelos branquinhos e ralos, rostos enrugados, mãos e pés envelhecidos. Elas aparecem sérias, nunca sorridentes nem serenas, e se aproximam lentamente. Às vezes com velas acesas nas mãos, às vezes somente caminhando bem devagar na direção da criança.

Não posso deixar de mencionar que de todas as crianças com as quais conversei nenhuma delas chegou a ouvir o pedido de qualquer alma para que rezasse. "É que não dá tempo", me explicou o pequeno capuxu, "nós grita tanto, que elas vão-se embora". É assim que nunca nenhuma criança pôde ter certeza da real intenção dessas almas que lhes aparecem nos cantos recônditos da casa, mas os adultos lhes dizem para acalmá-los: "era só para pedir rezas".

Por via das dúvidas, passam as crianças a fazer orações intermináveis antes de dormir, com ou sem terços em suas mãozinhas. Uma avalanche de ave-marias e pais-nossos é proferida, sempre com bastante fé, joelhinhos aos pés da cama, dedinhos das mãos cruzados e olhos bem fechados, tudo em nome da alma de finado fulano ou finada fulana, ${ }^{15}$ na esperança de que as almas não voltem mais para fazer pedidos.

Se esses malassombros são criados facilmente, eles também podem ser destruídos com a mesma facilidade. Por isso, as crianças pequenas não demonstram tanto medo dos malassombros, uma vez que, em relação a elas, os malassombros gozam de agência relativa. Sua agência é relativa porque é dividida com a própria criança, que tem o poder de criálo e destruílo, a bem da brincadeira e da diversão. Ao contrário, para o adulto, o malassombro tem agência absoluta, na medida em que é regulado por uma entidade religiosa. É esta entidade, em si mesma, a responsável pela sua aparição e pelos seus assombramentos (Pires 2009:307).

A discussão sobre a agência das crianças aventada por Pires é interessante. Em se tratando das crianças capuxu, sua agência fica evidente ao criarem estratégias para lidar com os malassombros ou ao tentarem burlar a sua aparição. Por isso mesmo não creio que em SantanaQueimadas o medo seja maior entre adultos, tal qual ocorre em Catingueira: "Desse modo, entendemos que o medo dos malassombros seja muito mais substancial na idade adulta e para as crianças maiores de dez anos de idade" (Pires 2009:308).

Pires defende que em relação aos mal-assombros "as crianças têm agência; já os adultos, são passivos" (Pires 2009:308). Em todo caso, o fato é 
que o malassombro diz respeito a toda a comunidade, seja no Sítio SantanaQueimadas, seja na cidade de Catingueira.

Fiod (2019) enfatizou a agência das crianças de Siwvle, no Haiti, ao despistar, desviar e enganar os lougawou graças à sua capacidade inventiva de criar proteção contra a magia de humanos e não humanos dentro do seu espaço familiar. Por meio desta agência as crianças tornavam-se pessoas adultas, donas de si.

Margaret Mead (1932) afirma que, entre os manu, da Nova Guiné, a crença nos fantasmas era uma característica da sociedade adulta não apresentada pelas crianças. A antropóloga pediu às crianças que desenhassem livremente e constatou que pouquíssimas desenharam fantasmas - enquanto entre adultos os fantasmas eram temas constantes nas conversas. Mead concluiu que os fantasmas eram uma précondição da sociedade adulta - exatamente ao contrário da sociedade norteamericana, que servia como contraponto para a antropóloga.

Entre os Capuxu os malassombros são um apanágio das relações sociais. Ninguém vive na comunidade e prevalece incólume à experiência com os malassombros, sendo este um atributo da pessoa capuxu. Ora, se a experiência com os malassombros diz respeito ao valor que os Capuxu atribuem às relações entre as pessoas, por que razão ficariam de fora da experiência as crianças? Além disso, há um aspecto essencial quanto à vida no campo: o fato de que universos adulto e infantil estão emaranhados. Ao contrário do que ocorre nas cidades, onde muitas vezes se mantêm as crianças longe de velórios, cemitérios e de qualquer coisa que remeta à morte, existindo inclusive espaços apropriados para isso, como funerárias e cemitérios, em Santana-Queimadas os corpos são velados em casa, e as dimensões adulto e criança estão emaranhadas em todos os sentidos, e porque não, também, no que se refere à experiência com o sobrenatural?

Apesar da crença de que certas almas-malassombradas venham realmente pedir reza, parece haver uma concordância geral de que a alma voltar para a terra não é coisa boa. Por isso, o que se puder fazer para que ela não apareça é bom que se faça. Dormir com alguém, não ficar sozinho pode ser uma solução. Assim é que as crianças optam sempre por ter um companheiro ao lado, na cama, no quarto ou em outra rede na sala, desde que não estejam sozinhas. Acredita-se que a alma nunca aparecerá para duas pessoas ao mesmo tempo, preferindo sempre aparecer para uma de cada vez. "Não sei por que não aparece pra duas logo, só assim economizava [aparição] e conseguia mais rezas", retrucou o menino de 7 anos, aborrecido com os temores que lhe tiram o sono e com a irracionalidade das almas. 
Preocupada com a minha própria noite de sono, depois de todas aquelas conversas, e sem ocultar de meus pequenos interlocutores o medo de alma que eu ainda carrego da criança sertaneja e camponesa que fui, perguntei o que eu poderia fazer para que elas não aparecessem para mim. Assim eles me ensinaram: "se tiver dormindo de rede e sentir alguém puxando os punhos da rede, diga bem alto 'quem pode mais do que Deus?' três vezes: 'quem pode mais do que Deus?', 'quem pode mais do que Deus?', 'quem pode mais do que Deus?'. Esperando que ninguém nunca responda: 'eu!'". Antropóloga inconveniente que sou, foi a minha vez de retrucar: "não era mais fácil dizer logo 'ninguém pode mais do que Deus!', pra não correr o risco de, fazendo pergunta, ela responder?". O menino discordou: "é assim mesmo que tem que dizer, 'quem pode mais do que Deus?', que ela sabe que não pode e vai-se embora".

Percebamos como a alma se apropria do corpo que tinha para que possa ser vista e fazer pedidos a alguém. ${ }^{16}$ Embora o seu grande trunfo esteja no campo visual e que basta ser vista para surtir o efeito de assustar, as almas nunca se dispõem ao toque de outros corpos. No máximo, se as crianças escondem seus rostos em lençóis, redes ou travesseiros, fugindo assim do campo visual que uma alma leviana deseje ocupar, elas fazem barulhos, puxam punhos de redes ou pontas de lençóis para chamar a atenção.

Aliás, há somente uma situação em que a alma pode tocar o corpo dos vivos: quando, não dando certo todas as tentativas, a criança insiste em se esconder debaixo dos lençóis, ela deve cuidar para que seus pés não fiquem fora do lençol, pois uma alma certamente o tocará, ou "puxará o pé" da criança. Assim, se alguma criança faz uma brincadeira ao longo do dia com alguém que já morreu ou ofende sua memória, mil ameaças recairão sobre ela (feitas pelos adultos e pelas outras crianças) dizendo que a alma da pessoa virá "puxar seu pé" de noite.

Interessante destacar que as almas-malassombradas que aparecem são geralmente de pessoas conhecidas, velhinhos ou velhinhas que morreram no Sítio, ou são dos sítios vizinhos. Mesmo em se tratando de pessoas com as quais se tem algum parentesco, avós, tios-avós etc., ver almas não é, em circunstância nenhuma, uma coisa boa.

Embora as assombrações estejam presentes tanto no universo das crianças como no dos adultos, as crianças falam mais sobre isso, e se dedicam a pensar em malassombros em vários momentos do dia. Em geral os pais não discordam das crianças e dizem que determinado malassombro existe de fato e pode aparecer para qualquer pessoa, a não ser quando uma criança pequena se põe a chorar em demasia de medo, insistindo que não é verdade, quase suplicando aos pais: "digam a verdade: alma-malassombrada não 
existe". Para que possam dormir em paz e acalmar a criança, os pais dizem que é tudo mentira, "história inventada", que quem morre fica no céu ou no inferno e que de lá não pode sair sob nenhum pretexto.

Quanto aos lugares mais úteis à aparição de malassombros, devo dizer que, segundo as crianças, embaixo da cama é um dos lugares favoritos das almas-malassombradas. Nisto coincidem almas e crianças, que também adoram brincar de se esconder debaixo das camas. Talvez por isso elas acreditem que as almas-malassombradas apreciem esconder-se debaixo de suas camas para as assombrarem. ${ }^{17}$ Por esta razão, há sempre um ritual antes de dormir: depois das rezas, ainda de joelhos, averiguar se não há, lá embaixo da cama, uma alma bem escondida esperando que a criança esqueça o pé do lado de fora do lençol ou da própria cama para que possa puxá-lo.

Além de embaixo das camas, outro lugar dileto das almas são as redes armadas em seus tornos de parede a parede e vazias durante a noite. Por conta disso, sempre que se dirigem aos seus quartos e a outros lugares de dormir, as famílias desarmam as redes enrolando-as num torno, deixando-a pendurada para se assegurar que nenhuma alma virá dormir nela durante a noite. Foi pensando na mesma possibilidade que, na casa fechada cuja última dona morreu, a cadeira de balanço foi retirada do chão e pendurada em um torno na parede, para que nenhuma alma, sentindo-se cansada, se utilizasse dela para descansar.

O horário mais comum para a aparição das almas-malassombradas é à noite, quando todos já estão deitados ou dormindo, até a madrugada, sempre antes do dia nascer, pois são notívagas as almas-malassombradas do Sítio Santana-Queimadas. Pontualmente às 18 horas, também chamada de "a hora dos anjos", é possível ver almas-malassombradas, e daí em diante, até antes da alvorada.

No que se refere às pessoas, como foi mencionado acima, as crianças são as mais visitadas pelas almas, as que têm mais histórias para contar sobre elas, embora os adultos sempre tenham uma experiência com malassombro acontecido na infância ou quando adulto para contar às crianças, que escutam atentas nas calçadas do Sítio durante a noite e voltam assustadas para suas casas, sempre dando uma olhadinha embaixo da cama antes de dormir. 


\section{De outros malassombros}

- A botija ou os sonhos de aviso

Alguns malassombros muito presentes no universo adulto terminam sendo disseminados entre as crianças. Um deles é a lenda da botija ou do "sonho de aviso". ${ }^{18}$ Contam os habitantes do Sítio que antigamente os fazendeiros tinham suas riquezas transformadas em joias e, devido à inexistência de bancos e à insegurança dos cofres caseiros, eles enterravam seus pertences sob os pisos de suas casas, no intuito de resguardá-los dos cangaceiros que na época percorriam as fazendas em busca de riquezas.

Quando morriam repentinamente, as joias ficavam espalhadas sob os pisos das casas da fazenda. Anos depois, a alma do finado fazendeiro aparecia em "sonhos de aviso" para alguém a quem desejasse dar a sua fortuna. O espírito aparecia durante três noites consecutivas num sonho repetitivo dizendo onde a botija estava escondida.

Junto às revelações, há uma série de critérios a serem obedecidos. São estes, grosso modo: ir à meia-noite, não levar nada para iluminar o lugar, não contar a ninguém sobre o sonho. Ademais, já se sabe que o "sortudo" enfrentará uma série de assombrações durante o processo para desenterrar a fortuna: "vê alma-malassombrada, sente calafrio, sente picada de formiga sem ter nenhuma, ouve correntes e passos, vê tochas". Acredita-se também que, após "arrancar a botija", o beneficiado deve se mudar da comunidade, senão ele morrerá.

Um dia, um velho capuxu foi tirar uma botija, sofreu tudo isso e não resistiu, correu. Quando voltou no dia seguinte para pegar as alpercatas, não havia sinal delas. O cimento da casa tinha sido reconstruído, os instrumentos largados na hora da fuga sumiram e suas sandálias também. Mas é como me dizem as crianças: "ninguém conhece ninguém que tenha conseguido pegar uma botija, mas dizem por aí que tem".

\section{- A morte anunciada}

Outro tipo de malassombro comum entre este povo é a ideia de que a morte, antes de vir buscar alguém, chama por ela. Assim, eles me dizem: "se você ouvir alguém chamando seu nome do nada, numa estrada, ou estando sozinha em casa e ouvir alguém chamando você, não responda, é a morte". Os adultos e as crianças acreditam que a morte chama o nome da vítima nas vésperas de vir buscá-la; caso a vítima responda, a morte está autorizada a vir, do contrário, ela desistiria e o sujeito se livraria da "passagem". 
A notícia de que a morte ronda uma casa ou família e que uma tragédia se aproxima é também anunciada pela rasga-mortalha. ${ }^{19}$ Ela seria a anunciadora de maus-agouros. Ela emite um som estridente que, ao ser ouvido, deixa os Capuxu arrepiados. O barulho das suas asas ao bater lembra também o som de um tecido sendo rasgado, neste caso associado à mortalha utilizada pelos defuntos ao serem enterrados, o que lhe conferiu a designação de "rasga-mortalha".

- Visagem da tocha

No roçado também é possível ver aparições de almas-malassombradas, mas a mais comum pelos roçados é a chamada "visagem da tocha". A tocha consiste num ente sobrenatural que aparece sob forma de uma tocha de madeira com fogo na ponta nos roçados durante a noite. Os donos dos roçados se assustam e, preocupados com as suas plantações, vão em busca da tocha para apagá-la, livrando sua produção do fogo. Eles correm munidos de latas e baldes carregados com água de casa, caso perto do roçado não haja um lugar de onde se possa tirar a água. Vão sozinhos ou com a ajuda da esposa, de vizinhos ou filhos, mas na medida em que se aproximam, a tocha se afasta, e ao chegarem ao roçado nada encontram, nem mesmo qualquer sinal de que houvera fogo. Assim, a visagem da tocha é caracterizada por este aparecer/desaparecer misteriosamente, sem que ninguém tenha conseguido chegar perto dela.

Além das casas, as estradas do Sítio à noite também são lugares profícuos para o aparecimento de almas-malassombradas ou visagens. Por isso, as crianças não costumam caminhar pelas estradas à noite, e se o fazem, buscam sempre ir na companhia de alguém, a largos passos, olhando constantemente para trás para se certificarem de que nenhuma alma-malassombrada as persegue.

\section{- Casas malassombradas}

Além da alma-malassombrada, que geralmente é vista no espaço da casa, e raras vezes pelas estradas do Sítio Santana-Queimadas ou roçados, encontramos as chamadas casas malassombradas, disseminadas pelo Sítio e na imaginação das crianças capuxu. Conforme Pires (2009) havia enunciado,

Os malassombros se dão a ver principalmente em três lugares: 1. no cemitério, onde há as mais altas taxas de aparição de malassombro constatadas na pesquisa; 2. na natureza, em lugares ermos, afastados das cidades, como os 
sítios e as florestas / matas (é comum os fantasmas serem desenhados "indo para a cidade", "assombrando a cidade", "invadindo a cidade"); 3. nas casas malassombradas, que podem ser divididas em (a) casas velhas abandonadas, algumas vezes afastadas das cidades e (b) casas onde moram os vivos. Os malassombros podem fazer parte da família que ali habita ou habitava - mas isso não acontece necessariamente (Pires 2009:297).

A casa malassombrada entra no rol dos espaços do Sítio onde podemos encontrar almas-malassombradas. ${ }^{20}$ A casa abandonada ou em ruínas é o lugar mais propício, seguida do matagal, das estradas e dos roçados, mas nestes quase sempre à noite. O Sítio Santana-Queimadas não possui um cemitério sendo os mortos do Sítio enterrados no cemitério da cidade de Santa Terezinha, município ao qual o Sítio pertence. O cemitério, é claro, é sempre um dos lugares mais propícios ao aparecimento das almas-malassombradas, na falta de um, devemos considerar que as almas-malassombradas, a princípio, poderiam e podem aparecer em qualquer lugar, mas há lugares que são mais propensos a serem habitados ou visitados por elas. ${ }^{21}$ Por conta disso, as crianças evitam como podem as casas fechadas, abandonadas ou em ruínas. Especialmente se tivessem pertencido a alguma velhinha ou velhinho que morreu deixando a casa fechada ou abandonada. É o caso da casa de uma senhora que morreu há poucos anos e cujos pertences ainda estão guardados na sua casinha.

É preciso atentar para a diferença entre casa abandonada e casa fechada. No caso da casa fechada, embora ninguém more nela, os familiares têm a chave, as coisas do morto permanecem, em geral, no lugar, e assim ela ficará por muito tempo, até que uma nova família se construa, e na falta de lugar para morar, decida reformar a casa e habitá-la. Mas ela será sempre "a casa onde fulano(a) morreu", pois se alguém morreu em casa, as chances de que não queira deixá-la são maiores, a casa sendo sempre associada à pessoa e vice-versa.

Se a casa foi abandonada, não terá portas nem janelas e, em geral, nenhuma mobília, sendo lugar perfeito para habitarem as almas que já não precisam mesmo de mobília. Para as crianças, depois dos cemitérios, casas fechadas ou abandonadas são os lugares preferidos para morarem as almas-malassombradas. Por isso é que as crianças evitam, como podem, as casas malassombradas. Apesar de sua insistência em transformar todos os espaços em lugar para brincadeiras e do potencial que uma casa deste tipo teria, especialmente para as meninas brincarem de rancho (casinha), ninguém aventa esta possibilidade. Está fora de cogitação querer frequentar casas abandonadas e fechadas, ou fazer brincadeiras de esconde-esconde, 
toca ou de qualquer outro tipo nos seus arredores ou no seu interior, especialmente se já passar do entardecer.

Assim, além da própria casa da criança, onde ela aparece quando tem vontade, se a criança for a uma casa abandonada ou em ruínas, definida previamente como casa malassombrada, ou seguir pelas estradas do Sítio, matagal ou roçados à noite, as chances de que uma alma venha ter com ela para lhe pedir rezas aumentam. Em geral, as almas-malassombradas são notívagas, sendo raros os casos em que contam terem visto almas em roçados durante o trabalho de dia. Mas os roçados podem ser visitados por almas, em situações pouco comuns, durante o dia, aparecendo para os adultos, como afirmei. Seriam antigos donos do roçado que vêm para verificar a plantação e os cuidados com a terra, revelando a conexão entre vivos e mortos também presente naquela relação que é a mais forte entre camponeses: sua ligação com a terra e o trabalho (Heredia 1988; Moura 1978; Woortmann 1983, 1995).

\section{Considerações finais}

Este artigo nasce com a complexidade inerente ao próprio sistema de crenças a que se dedica: a noção de malassombro entre as crianças capuxu. E se constrói a partir de percepções que são produtos da experiência das crianças com o sobrenatural. É importante perceber que, ao mesmo tempo em que para ser pessoa é preciso ter corpo e alma, denominam-se "pessoas mortas" as almas-malassombradas que aparecem sem um corpo palpável, ou seja, há um corpo, mas ele não é real. A prova disto é que é capaz de atravessar superfícies materiais. Embora digam que elas não são pessoas, as crianças atribuem às almas-malassombradas atributos de pessoa.

Assim, em um sistema de crenças extremamente complexo, as crianças capuxu navegam por noções e contradições a respeito da vida e da morte; do corpo, da alma e da pessoa; da alma dos vivos (esquecida enquanto se vive) e da alma dos mortos, que perambula sem poder ser tocada, a chamada alma-malassombrada.

A contradição é a sua marca: faz menção a aspectos religiosos por hábito, sem que haja de fato qualquer religiosidade essencial, dialoga com noções de bem e mal, Deus e o diabo entre adultos, mas não entre crianças. Enquanto há vestígios de uma religiosidade por trás de todas estas noções para os adultos, as crianças as ressignificam e utilizam os mesmos elementos a partir de significações e sentidos distintos. 
Neste artigo analisei como a experiência com o malassombro vivenciado pelas crianças capuxu não parece estar conectada à religiosidade do povo, mas operar através de um sistema de costumes. Em um contraponto com Pires $(2009,2010,2011)$ e avaliando a sua escolha metodológica, penso que é necessário, sempre que o campo assim o fizer, dissociar as representações de adultos e crianças. Acredito que, preocupada em não isolar as crianças e mostrá-las como sujeitos que detêm representações compartilhadas com os adultos sobre uma dada realidade, Pires concluiu que, por compartilharem das mesmas crenças, adultos e crianças estavam ligados a elas pela religiosidade. Suponho ser possível que adultos e crianças de uma dada comunidade partilhem os mesmos sistemas de crenças, símbolos ou códigos, mas atribuindo-lhes sentidos diferenciados. Logo, é preciso dissociar, quando necessário, representações, experiências e atribuições de sentidos de adultos e crianças.

Enquanto os adultos estabelecem uma relação direta entre religiosidade e malassombro, as crianças apreendem o sistema através do costume. Quando a criança profere "quem pode mais do que Deus?", ela repete a frase como uma espécie de jogo de palavras mágicas, um mantra, que faz desaparecer as almas-malassombradas. Quando os adultos passam a ideia de malassombro para as crianças, elas retêm o básico: "faz medo porque quem morre não deve voltar, se volta, tem alguma coisa errada"; "é só dizer quem pode mais do que Deus que ela vai-se'mbora". Ao proferirem estas afirmações, as crianças não se remetem a toda a complexidade do sistema religioso conforme fazem os adultos. Por isso, no caso capuxu, afirmamos que os adultos constroem essas noções a partir da religiosidade, mas as crianças veem sentido nos malassombros por eles mesmos, independe da religião. ${ }^{22}$

Pires (2009, 2010, 2011), ao tentar associar adultos e crianças nas mesmas representações, procurando demonstrar que malassombro não é coisa de crianças, pois adultos também temem, termina por defender que o processo de cristianização começa a partir dos 7 anos, e que nessa ocasião acontece no processo de cristianização uma associação entre religião e malassombro. A autora afirma que esta é a marca da passagem de crianças para adultos, quando no processo de cristianização os malassombros deixam de ter um sentido neles mesmos, e passam a ter um sentido religioso.

Isso nos remete à necessidade de sermos cautelosos ao pensarmos representações de crianças, jovens, adultos, idosos como comuns. Às vezes, crianças e jovens, adultos e idosos podem compartilhar de um mesmo repertório de crenças, mas imputar sentidos diferentes a ele. É preciso estar atento, pois é possível que se tenha o compartilhamento de um repertório comum, mas uma atribuição de sentido diferenciada a partir de cada fase do 
ciclo da vida. Esta é uma lição a ser retirada da experiência de Pires (2009, 2010) com as crianças e os mal-assombros em Catingueira.

Também Fiod (2019) percebeu diferenças na atribuição de intenção e na concepção de maldade dos ataques de lougawou quando narrados por crianças e adultos em Siwvle.

As crianças estão inseridas em um conjunto de relações que não podem escolher: são filhas, afilhadas, sobrinhas e netas dos potenciais agressores, e podem ser, ainda, submetidas a tratamentos conduzidos por eles. No entanto, esta perspectiva não dá conta do que as crianças fazem e falam sobre o que fazem quando estão longe dos adultos. Elas procuram maneiras de despistar os lougawou e de se proteger dos próprios tratamentos feitos pelos membros de suas famílias (Fiod 2019:307).

Essa complexidade do sistema de crenças de malassombros para os Capuxu atravessa todo este artigo, no qual tentativas vãs de classificar e hierarquizar categorias como religiosas ou não torna ainda mais complexa a discussão. O malassombro, enquanto sistema de crenças, cumpre uma função que acredito ser a de manter mortos e vivos em contato.

Percebemos aqui como a agência infantil atravessa as percepções de alma-malassombrada, sempre criando estratégias para que elas não apareçam, erguendo cadeiras de balanço, enrolando as redes de dormir, mantendo os pés sob os lençóis, averiguando embaixo da cama antes de dormir ou agradando as almas dos mortos com orações intermináveis. Todas estas atitudes revelam a autonomia das crianças e a sua agência, pois, apesar de os adultos ou as crianças maiores lhes transmitirem histórias de aparições de almas-malassombradas quase inevitáveis, elas se esforçam para burlar as regras dificultando as tentativas de aparecimento das almas penadas. A verdade é que as crianças fazem o que podem para, num lugar onde as pessoas e as relações são o que importa, não estabelecer contato com as almas dos mortos, ao mesmo tempo em que esta agência pode ser percebida na invenção do próprio malassombro, como demonstrou Pires (2009).

Como vimos, este universo de crenças em malassombros é na verdade comum ao povo Capuxu, algumas das crenças sendo ensinadas pelos adultos e praticadas pelas crianças que passam a vivê-las no cotidiano. É assim que as crianças se utilizam do acervo dos adultos. Outras crenças são de conhecimento das próprias crianças, e ensinadas e ensaiadas entre pares, algo que, na maioria das vezes, os adultos - que a vivenciaram também na infância - nem se lembram mais. O importante é que mesmo no caso em que a crença transita do universo adulto para o infantil - estando estes dois universos sempre interligados em se tratando do mundo camponês - 
a criança exerce neles uma função essencial: ou com uma participação efetiva nos rituais ou, pelo menos, como a responsável por transmiti-los ainda na infância, ou mais tarde quando adulta, às próximas gerações.

Em alguns casos estas crenças infantis não fazem parte do universo geral de crenças da comunidade, ou seja, não dizem respeito a crenças compartilhadas pelos adultos. Isto nos remete à discussão sobre a autonomia do universo infantil abordada por autores como Cohn (2005), Fernandes (2004 [1946]), Hardman (1973), Hirschfeld (2002), Tassinari (2007) e Sousa (2018) em diferentes contextos.

Assim é que o sistema de crenças capuxu é constituído por uma série de crenças, fenômenos e rituais, alguns de autoria dos adultos, mas captados pelas crianças que se servem deste acervo, e outros de autoria das crianças e compartilhados entre elas. O compartilhamento de um mesmo acervo por adultos e crianças, em geral, é revelador do mundo camponês, onde o universo infantil e o universo adulto estão emaranhados e são indivisos, conformando um único modus de vida camponês.

Recebido em 28 de abril de 2020

Aprovado em 07 de janeiro de 2021

Emilene Leite de Sousa

Pós-doutorado em Antropologia pela UFPB. Doutorado em Antropologia Social pelo PPGAS/UFSC. É professora do PPGS da Universidade Federal do Maranhão. Autora da obra Umbigos enterrados: corpo, pessoa e identidade Capuxu através da infância, publicado pela EDUFSC. Pesquisadora do GECI/ UFMA e do CRIAS/UFPB.

https://orcid.org/0000-0003-2608-6677

E-mail: emilenesousa@yahoo.com.br 


\section{Notas}

1 Opto pela grafia do termo sem o hífen (geralmente é grafado como malassombro) em respeito à pronúncia peculiar dos Capuxu, cuja sonoridade é dada pela junção das duas palavras.

2 A noção de agência aqui considerada a partir de Giddens (2003) atribui ao ator a capacidade de processar a experiência social e de formular modos de enfrentar a vida, mesmo sob as mais diversas formas de coerção. Assim, reconhecemos a agência das crianças, uma vez que elas resolvem problemas, aprendem como intervir na realidade e monitoram suas próprias ações através da observação de como os outros reagem ao seu comportamento. Conforme Giddens (2003), a agência não diz respeito às intenções dos indivíduos de fazerem determinadas coisas, mas à sua capacidade de fazê-las, tornando-se essencial que os atores sociais vençam as lutas que ocorrem pela atribuição de significados sociais específicos a determinados acontecimentos, ações e ideias. Sobre a capacidade das crianças capuxu de modificarem a organização social do grupo, recomendo Sousa (2014).

3 Chamam de Outros aqueles povos que habitam os sítios vizinhos que fazem fronteira com o Sítio Santana-Queimadas, os moradores das cidades circunvizinhas e todos aqueles que convivem ou estabelecem relações cotidianas ou extraordinárias com o povo Capuxu e que não são Capuxu.

4 A entonação peculiar no modo como pronunciam as palavras é um importante sinal diacrítico do povo - que os torna facilmente reconhecidos em qualquer lugar pelo chamado "sotaque" - que trata da musicalidade peculiar da fala do grupo.

5 Primo carnal, nomenclatura mais comum entre o povo Capuxu, é um termo popular que designa os filhos de "casamentos trocados", isto é, quando dois filhos de uma mesma família se casam com dois filhos de outra família, seus filhos sendo considerados primos-irmãos ou primos carnais.

6 "[...] what is a ghost but an invisible dead person with a mind?" (Bering 2003:246)

7 " $[\ldots]$ holds unequivocally that ghosts should be no different than living people when it comes to basic psychological functioning, at least as they are represented in human minds" (Bering 2002:267).

8 "The concept [ghost] is that of a person who has counterintuitive physical properties. Unlike other persons, ghosts can go through solid objetcs like walls. But notice that apart from this ability, ghosts follow very stricly the ordinary intuitive concept of PERSON" (Boyer 2001:73).

9 Conforme Seeger et al. (1979), a produção física de indivíduos remete à produção social da pessoa. Entretanto, o corpo não é o único instrumento através do qual a sociedade atua sobre os indivíduos, outros instrumentos contribuem para construção da pessoa, entre eles estão os complexos de nominação e as teorias sobre a alma (Seeger et al. 1979). 
10 Atenta aos processos de crescimento, fortalecimento e aprendizagem das crianças de Siwvle, no Haiti, Fiod revela a importância de conhecimentos sobre o corpo, os espíritos e as heranças familiares no "processo de formação da pessoa" (Fiod 2019:206).

11 Fiod destaca que as crianças em Siwvle aprendem a lidar com espíritos por meio dos adultos e entre seus pares, possuindo uma forte "capacidade inventiva", revelada na operacionalização de conceitos em estratégias, neste caso, de proteção contra feitiços e ataques de parentes e vizinhos (Fiod 2019).

12 Conforme Fiod (2015), as crises noturnas vividas pelas crianças de Siwvle eram atribuídas aos lougawou de forma genérica pelos adultos, mas não pelas crianças, que as identificavam geralmente com um parente ou vizinho específico e normalmente próximo a elas, revelando uma diferença entre as percepções de adultos e crianças sobre os lougawou. Além disso, sentir-se ameaçado pelos familiares lougawou fazia as crianças traçarem estratégias à revelia dos adultos para se defenderem, demonstrando a importância da agência das crianças.

13 Os adultos em geral dizem que as almas que aparecem visam pedir rezas, já as crianças se dividem, as menores dizendo que elas vêm "só pra assombrar a gente" e as maiores repetindo aquilo que dizem e lhes ensinaram os adultos: "é por causa das rezas".

14 Ousaria dizer, por estranho que pareça, que pedir reza parece estabelecer uma conexão entre malassombros e religiosidade, mas não entre as crianças e o cristianismo.

15 Utilizar sempre a nomenclatura finado ou finada antes do nome do morto é uma forma de respeito que os camponeses prezam muito. Ademais, para as crianças, este tratamento, por demonstrar respeito pela alma do defunto, pode mantê-lo longe de visitas noturnas e pedidos de rezas. É também comum sempre pronunciar, após o "finado fulano", a expressão "Deus o tenha em bom lugar".

16 Roberto DaMatta (1997) fez uma interessante análise da morte e seus fenômenos, defendendo que as aparições dos mortos não se trata apenas de uma questão de sobrevivência da alma, mas revela a cosmovisão de uma sociedade relacional, isto é, que acredita mais nas relações sociais do que nos indivíduos que lhes dão forma e vida. O autor afirma que "vivemos em um universo onde os vivos têm relações permanentes com os mortos e as almas voltam sistematicamente para pedir e ajudar, para dar lições de humildade cristã aos vivos, mostrando sua assustadora realidade" (DaMatta 1997:146).

17 Voltamos aqui ao raciocínio psicologizante de Bering (2003), para quem as crianças atribuem às almas as características de sua própria mente.

18 Pires (2011) analisou a assombração da "botija de ouro" como são chamados em Catingueira os sonhos de aviso. Segundo a autora, "as botijas de ouro são um tema muito interessante de pesquisa e podem render contribuições para o estudo da economia, do cangaço, da religião, do parentesco e da família na região do semiárido nordestino" (Pires 2011:111). 
19 De acordo com Pires, a rasga-mortalha "é uma espécie de coruja de nome Tyto alba, conhecida ainda como suindara ou coruja-de-igreja. É um pássaro negro com o ventre branco que anuncia morte preeminente ou mau agouro, quando sobrevoa uma residência" (Pires 2011:123). A autora verificou a existência desta coruja em Catingueira e a crença de que ela não só anuncia a morte iminente, mas também "para confirmar sua predição, ela aparece no velório daquele cuja morte anunciou, a fim de acompanhar o enterro" (Pires 2011:123).

20 Damalso (2018) observou em sua pesquisa no Haiti que "os espaços não são habitados apenas por pessoas, mas também pelos mortos (lemò) e por espíritos que fazem parte da família" (Damalso 2018:99).

21 Delumeau (1996) acreditava que os fantasmas, além de anunciarem desgraças, eram os habitantes das casas mal-assombradas. De tão levado a sério os medos de fantasmas, um item era incluído nos contratos de aluguel: em 1586 os juristas explicavam que um locatário não precisaria pagar as anuidades combinadas se a casa alugada fosse assombrada e isso provocasse um medo genuíno.

22 Damalso (2018) demonstrou que os lwa são parte fundamental da experiência social das pessoas em Jacmel, "atingindo-as diretamente, influenciando suas ações e interferindo em seus destinos independentemente de suas filiações religiosas" (Damalso 2018:98). 


\section{Referências bibliográficas}

BARTH, Fredrik. 2011. "Grupos étnicos e suas fronteiras". In: Philippe Poutignat \& Jocelyne Streif-Fenart, Teorias da Etnicidade: seguido de grupos étnicos e suas fronteiras de Fredrik Barth. São Paulo: Editora Unesp.

BAUMAN, Zygmunt. 2008. Medo Líquido. Rio de Janeiro: Jorge Zahar Editora.

BERING， J. M. 2002. "Intuitive conceptions of dead agent's minds: the natural foundations of afterlife beliefs as phenomenological boundary". Journal of Cognition and Culture, 2 (4):263308.

. 2003. "Religious concepts are probably epiphenomena: a reply to Pyysiäinen, Boyer and Barret". Journal of Cognition and Culture, 3 (3) :244254.

BRAITE, Fernanda. 2019. O fantasma em narrativas de horror da literatura brasileira. Dissertação de Mestrado em Literatura Crítica e Crítica Literária, Programa de Estudos PósGraduados em Literatura e Crítica Literária, PUC-São Paulo.

BOYER, Pascal. 2001. Religion Explained: The Evolutionary Origins of Religious Thought. Nova York: Basic Books.

COHN, Clarice. 2005. Antropologia da Criança. Coleção Passo a Passo, 57. Rio de Janeiro: Jorge Zahar

DALMASO, Flávia. 2018. "Heranças de família: terras, pessoas e espíritos no sul do Haiti". Mana, 24 (3):96-123.

DAMATTA, Roberto. 1997. A casa e a rua: espaço, cidadania, mulher e morte no Brasil. 5. ed. Rio de Janeiro: Rocco.

DELUMEAU, Jean. 1996. História do Medo no Ocidente, 13001800: Uma Cidade Sitiada. São Paulo: Companhia das Letras.
FERNANDES, Florestan. 2004 [1946]. "As trocinhas do bom retiro: contribuição ao estudo folclórico e sociológico da cultura e dos grupos infantis". In: __, Folclore e Mudança Social na cidade de São Paulo. São Paulo: Martins Fontes.

FIOD, Ana. 2015. Lougawou: feitiço, famílias e crianças em Siwvle, Haiti. Dissertação de Mestrado, Programa de Pós-Graduação em Antropologia Social, Museu Nacional, Universidade Estadual do Rio de Janeiro.

. 2019. "Feitiço". In: F. Neiburg (org.), Conversações etnográficas haitianas. Rio de Janeiro: Papéis Selvagens.

GIDDENS, Anthony. 2003. A constituição da Sociedade. 2. ed. São Paulo: Martins Fontes.

GODOI, Emília Pietrafesa de \& MELLO, Marcelo Moura. 2019. "Entre seres intangíveis e pessoas: uma introdução". Etnográfica [on-line], v. $23(2)$..

HARDMAN, Charlote. 1973. "Can there be an anthropology of children?". Journal of the Anthropological Society of Oxford, v. IV, n. 2:85-99. Republicado em 2001. Childhood, v. 8 (4) :501-517.

HEREDIA, Beatriz M. Alásia de. 1988 [1979]. A morada da vida: trabalho familiar de pequenos produtores do Nordeste do Brasil. Rio de Janeiro: Paz e Terra.

HIRSCHFELD, Lawrence. 2002. "Why don't Anthropologists like Children?", American Anthropologist, 104 (2) p.611-627.

MARTíN, Maria Eloísa. 2001. Genuinamente correntina. Um estudo antropológico da experiência católica na festa da Virgem de Itatí. Dissertação de Mestrado em Antropologia Social, PPGAS/UFGRS. 
MAUSS, Marcel. 2003 [1969]. Sociologia e Antropologia. São Paulo: Cosac \& Naify, 2003.

MEAD, M. 1932. "An investigation of the thought of primitive children, with special reference to animism". Journal of the Royal Anthropological Institute, 62:173190.

MOURA, Margarida Maria. 1978. Os herdeiros da terra: parentesco e herança numa área rural. São Paulo: Hucitec.

PIRES, Flávia. 2009. "Quem tem medo de mal-assombro?". Revista Etnográfica, Lisboa, n. 13 (2):291-312. 2010. "Tornando-se adulto: uma abordagem antropológica sobre crianças e religião". Religião e Sociedade, Rio de Janeiro, 30 (1):143164.

. 2011. Quem tem medo de malassombro?: religião e infância no semiárido nordestino. Rio de Janeiro: E-papers; João Pessoa: UFPB.

RODRIGUES, José Carlos. 2006. Tabu do Corpo. 7. ed. Rio de Janeiro: Fiocruz.

SCHILDKROUT, Enid. 1978. "Age and Gender in Hausa Society: SocioEconomic Roles of Children in Urban Kano". In: La Fontaine (ed.), Sex an Age as Principles of Social Differentiation. London: Academic Press.

SEEGER, A.; DAMATTA, R. \& VIVEIROS DE CASTRO, E. 1979. "A construção da pessoa nas sociedades indígenas brasileiras". Boletim do Museu Nacional, n. 32.

SILVA, Ana Márcia. 1999. O corpo do mundo: reflexóes acerca da expectativa de corpo na Modernidade. Tese de Doutorado, Universidade Federal de Santa Catarina, Florianópolis. p. 236.
SOUSA, E. L. 2004. "Que trabalhais como se brincásseis": trabalho e ludicidade da infância Capuxu. Dissertação de Mestrado, Programa de Pós-Graduação em Sociologia, Universidade Federal da Paraíba. . 2014. "Nomear é trazer à existência: a onomástica Capuxu (de crianças e de bichos) e os apelidos na produção da pessoa Capuxu". Revista Campos, 15 (1):71-97.

. 2017. Umbigos enterrados: corpo, pessoa e identidade Capuxu através da infância. Coleção Brasil Plural/Instituto Brasil Plural-IBP. Florianópolis: EDUFSC. 2018. Autonomia do Universo Infantil versus Autonomia Infantil: A Agência das Crianças no Contexto Camponês Capuxu. Temáticas - revista de pósgraduandos em ciências sociais da Unicamp, n. 51:181-182. Disponível em: https://www.ifch.unicamp.br/ ojs/index.php/tematicas/article/ download/3304/2443. Acesso em 15/02/2019.

SOUSA, E. L. 2020. "Capuxu - de vespa a grupo social: a produção da etnicidade em uma comunidade camponesa no sertão da Paraíba". Vivência: Revista de Antropologia, v. 1, n. 53, maio.

TASSINARI, Antonella M. I. 2007. Concepções Indígenas de Infância no Brasil. In Revista Tellus, ano 7, n.13, outubro, Campo Grande: UCDB, p.11-25

WAGNER, Roy. 2010. A invenção da cultura. São Paulo: Cosac Naify.

WOORTMANN, E. F. 1995. Herdeiros, parentes e compadres. São Paulo: Hucitec; Brasília: Ed. UnB. . 1983. "O sítio camponês". Anuário Antropológico, UnB-Brasília, n. 81:164-203. 
"QUEM PODE MAIS DO QUE DEUS?": AS CRIANÇAS CAPUXU E SUAS EXPERIÊNCIAS COM OS MALASSOMBROS

Resumo

Este artigo etnográfico objetiva analisar as experiências das crianças Capuxu com os malassombros. Ele é produto de uma pesquisa cujo objetivo era investigar a produção da pessoa Capuxu à luz da fabricação dos corpos das crianças. Foi assim que resvalei nas percepções sobre corpo e alma, dimensões da pessoa Capuxu, e dentro da categoria alma revelou-se o conceito nativo de malassombro, aqui abordado através de um diálogo com as noções de morte e medo. Além disso, analiso a agência infantil em estratégias cotidianas para afugentar os malassombros; a inexistência de relação entre a crença em malassombros e a religiosidade; e o reconhecimento de que adultos e crianças podem compartilhar do mesmo repertório de crenças, mas atribuir sentidos diferentes. Demonstro que os Capuxu representam os mortos como almas-malassombradas porque as pessoas e as relações é que são importantes e a morte não impede a tessitura de tais relações.

Palavras-chave: Crianças Capuxu. Morte. Medo. Pessoa. Malassombros.
“WHO'S MORE CAPABLE THAN GOD?" CAPUXU CHILDREN AND THEIR EXPERIENCES WITH MALASSOMBROS (HAUNTING)

\section{Abstract}

This article analyzes the experiences of Capuxu children with hauntings. It results from research aimed at investigating the production of the Capuxu person in light of the fabrication of children's body. This was how I came upon the theme of the body and soul, which are dimensions of the Capuxu person. Through the category of the soul, I discovered the native term malassombro (haunting), which I here investigate in dialogue with ideas of death and fear. Furthermore, I analyze children's agency in the context of their daily attempts at casting out such malassombros; the absence of a relation between belief in the malassombros and religiousity; and the recognition that adults and children may share the same repertoire of beliefs, but confer different meanings on them. I demonstrate that Capuxu people represent the dead as almas-malassombradas (haunted souls) because what matters are people and relations, and death does not prevent the unfolding of such relations.

Keywords: Capuxu Children. Death. Fear. People. Malassombros. 


\section{“¿QUIÉN PUEDE MÁS QUE \\ DIOS?" LOS NIÑOS CAPUXU \\ Y SUS EXPERIENCIAS CON \\ MALASSOMBROS (APARICIONES)}

\section{Resumen}

Este artículo etnográfico tiene como objetivo analizar las experiencias de los niños capuxu con malassombros. Este es el resultado de una encuesta en que se buscó investigar la cría del individuo capuxu a la luz de la configuración del cuerpo de los niños. De esta manera, indagué en las percepciones del cuerpo y el alma, las dimensiones de una persona Capuxu. A partir de la categoría de alma se reveló el concepto nativo malassombro (aparición), abordado aquí a través de un diálogo con las nociones de muerte y miedo. Además, analicé la agencia infantil en estrategias cotidianas para ahuyentar una aparición; la inexistencia de relación entre la creencia en estas apariciones y la religiosidad; y el reconocimiento de que adultos y niños pueden compartir el mismo repertorio de creencias, pero asignar diferentes sentidos. Demuestro que los Capuxu representan los muertos como almasmalassombradas (espíritus embrujados) porque las personas y las relaciones son lo que importa, y la muerte no impide la tesitura de tales relaciones.

Palabras clave: Niños Capuxu. Muerte. Miedo. Persona. Malassombros. 